\title{
A Microstructure Based Strength Model for Slag Blended Concrete with Various Curing Temperatures
}

\author{
Li-Na Zhang, ${ }^{1}$ Wang Xiao-Yong, ${ }^{1}$ and Kyung-Taek Koh ${ }^{2}$ \\ ${ }^{1}$ Department of Architectural Engineering, Kangwon National University, Chuncheon-Si 200-701, Republic of Korea \\ ${ }^{2}$ Structural Engineering Research Division, Korea Institute of Construction Technology, Goyang-Si 411-712, Republic of Korea \\ Correspondence should be addressed to Wang Xiao-Yong; wxbrave@kangwon.ac.kr
}

Received 7 October 2015; Accepted 24 November 2015

Academic Editor: Yuyin Wang

Copyright (c) 2016 Li-Na Zhang et al. This is an open access article distributed under the Creative Commons Attribution License, which permits unrestricted use, distribution, and reproduction in any medium, provided the original work is properly cited.

\begin{abstract}
Ground granulated blast furnace slag, which is a byproduct obtained during steel manufacture, has been widely used for concrete structures in order to reduce carbon dioxide emissions and improve durability. This paper presents a numerical model to evaluate compressive strength development of slag blended concrete at isothermal curing temperatures and time varying curing temperatures. First, the numerical model starts with a cement-slag blended hydration model which simulates both cement hydration and slag reaction. The accelerations of cement hydration and slag reaction at elevated temperatures are modeled by Arrhenius law. Second, the gel-space ratios of hardening concrete are calculated using reaction degrees of cement and slag. Using a modified Powers' gel-space ratio strength theory, the strength of slag blended concrete is evaluated considering both strengthening factors and weakening factors involved in strength development process. The proposed model is verified using experimental results of strength development of slag blended concrete with different slag contents and different curing temperatures.
\end{abstract}

\section{Introduction}

Granulated slag from metal industries is a steel industrial byproduct and can be used as a mineral admixture to produce normal and high strength concrete. It is broadly recognized that slag blended concrete has many advantages, including lower permeability, better chloride resistance, and higher strength at later ages. In addition, economics (lower cement requirement), energy, and environmental considerations can be achieved by using slag blended concrete $[1,2]$.

Compressive strength is the most important property of hardened concrete; other properties such as tensile strength, flexural strength, elasticity modulus, water tightness, and durability all are related to compressive strength closely. The compressive strength of slag blended concrete generally relates to materials properties, such as water to binder ratios and slag replacement ratios, and curing conditions, such as curing temperatures. Many experimental investigations have been done about strength development of slag blended concrete. Ramezanianpour and Malhotra [3] found that, for moist curing conditions, when slag replaces cement at $25 \%$ of total binder content, the early-age strength is lower than that of control concrete and the late age is higher than that of control concrete. While for slag replacing cement at $50 \%$, until the age of 90 days, the compressive strength is still lower than that of control concrete. Luan et al. [4] found when the slag content is less than $50 \%$ of total binder content, as slag content increases, the strength of concrete will increase correspondingly. After around $50 \%$ of the total binder content, the further addition of GGBS does not improve the compressive strength. So $50 \%$ of total binder content is the optimum content of slag. Eren [5] found that with the increasing of curing temperature, compared with that of standard curing at $20^{\circ} \mathrm{C}$, the early-age strength of slag blended concrete will increase. However, the late age strength will decrease.

Compared with abundant experimental study on strength development of slag blended concrete [3-5], theoretical models are very limited. To estimate compressive strength of concrete containing different supplementary cementing materials, Papadakis et al. $[6,7]$ proposed an efficiency factor of the SCM in an SCM-concrete. This efficiency factor describes the relative reactivity of SCM to cement. However, it should be 
noticed that Papadakis' model $[6,7]$ is not a kinetic model and only valid for standard curing condition. Ishida et al. [8] proposed a kinetic microstructure model to simulate cement hydration and slag reaction. The strength development is evaluated using reaction degrees of cement and slag. This kinetic model is valid for concrete with larger slag contents (60\% slag of total binder contents). But the effect of curing temperature on strength development is not considered in Ishida et al's study [8]. On the other hand, Brooks and AlKaisi [9] and Barnett et al. [10] proposed maturity functions to model the strength development of slag blended concrete at elevated temperatures. The ultimate strength becomes lower when curing temperature increases. However, it should be noticed that maturity function method belongs to a macroregression method. Cement hydration, slag reaction, and evolution of microstructure of hardening concrete are not detailedly considered in maturity function method $[9,10]$.

The development of mechanical properties of slag blended concrete relates to cement hydration and slag reaction. To overcome the weak points of current models [6-10], this paper puts forward a numerical procedure to simulate cement hydration, slag reaction, microstructure development, and strength development of slag blended concrete. The proposed procedure can reproduce strength crossover phenomenon of slag blended concrete with low curing temperatures and high curing temperatures. The proposed model is valid for slag blended concrete with different slag contents, different isothermal curing temperatures, and time varying curing temperatures.

\section{Modeling of Hydration of Cement-Slag Blends}

The development of concrete properties closely relates to hydration process. For hardening concrete, heat properties, mechanical properties, and chemical properties develop accompanied with cement hydration. For hardened concrete, compositions of hydration reaction products and capillary pore structures closely relate to degree of hydration. Hence modeling of hydration process is important for evaluating concrete properties. For cement-slag blends, cement hydration and slag reaction will occur simultaneously. To model hydration of cement-slag blends, we propose cement hydration model, slag reaction model, and interaction model between cement hydration and slag reaction.

2.1. Portland Cement Hydration Model. Tomosawa [11] measured the isothermal heat evolution rate of Portland cement paste. He found that cement hydration generally consists of three processes, that is, initial dormant process, phaseboundary reaction process, and diffusion process. Tomosawa [11] also presents a shrinking-core model to simulate the hydration of Portland cement. However, because Tomosawa's model does not consider the influence of capillary water concentration on cement hydration, this model is valid only for low strength concrete. For high strength concrete, due to the lower water to binder ratio, at late ages, capillary water concentration will significantly decrease, and rate of cement hydration will decrease correspondingly. Wang [12] revised
Tomosawa's model [11] to consider the effect of capillary water concentration on hydration. The revised equation is shown as follows [12]:

$$
\begin{aligned}
\frac{d \alpha_{i}}{d t} & =\frac{3\left(S_{w} / S_{0}\right) \rho_{w} C_{w-\text { free }}}{\left(v+w_{g}\right) r_{0} \rho_{c}} \\
& \cdot \frac{1}{\left(1 / k_{d}-r_{0} / D_{e}\right)+\left(r_{0} / D_{e}\right)\left(1-\alpha_{i}\right)^{-1 / 3}+\left(1 / k_{r i}\right)\left(1-\alpha_{i}\right)^{-2 / 3}}, \\
\alpha & =\frac{\sum_{i=1}^{4} \alpha_{i} g_{i}}{\sum_{i=1}^{4} g_{i}}
\end{aligned}
$$

where $\alpha_{i}(i=1,2,3$, and 4$)$ denotes reaction degree of mineral compound of cement $\mathrm{C}_{3} \mathrm{~S}, \mathrm{C}_{2} \mathrm{~S}, \mathrm{C}_{3} \mathrm{~A}$, and $\mathrm{C}_{4} \mathrm{AF}$, respectively; $\alpha$ denotes the degree of cement hydration; $k_{d}$ is the reaction coefficient in the initial dormant period; $D_{e}$ is the effective diffusion coefficient of water through the $\mathrm{C}-\mathrm{S}-\mathrm{H}$ gel; $k_{r i}$ is the reaction coefficient of boundary reaction process; $v$ denotes the stoichiometric ratio by mass of water to cement $(=0.25) ; w_{g}$ denotes the physically bound water in $\mathrm{C}-\mathrm{S}-\mathrm{H}$ gel $(=0.15) ; \rho_{w}$ denotes the density of water; $\rho_{c}$ denotes the density of the cement; $C_{w \text {-free }}$ denotes the amount of water at the exterior of the $\mathrm{C}-\mathrm{S}-\mathrm{H}$ gel; $r_{0}$ denotes the radius of unhydrated cement particles; $S_{w}$ denotes the effective surface area of the cement particles in contact with water; and $S_{0}$ denotes the total surface area if the surface area develops unconstrained.

As shown in (1b), reaction degree of cement $\alpha$ can be calculated from the weight fraction of mineral compound $g_{i}$ and reaction degree of mineral compound $\alpha_{i}$.

During initial dormant period, the formation of initial impermeable layer will lower rate of hydration, and the destruction of this impermeable layer will increase the rate of hydration. The reaction coefficient $k_{d}$ in the initial dormant period can be determined as follows:

$$
k_{d}=\frac{B}{\alpha^{1.5}}+C \alpha^{3}
$$

where $B$ describes the rate of the initial shell formation and $C$ describes the rate of the initial shell decay.

The effective diffusion coefficient of water $D_{e}$ relates to the tortuosity of the gel pores and the radii of gel pores in reaction products. $D_{e}$ can be described as a function of hydration degree as follows:

$$
D_{e}=D_{e 0} \ln \left(\frac{1}{\alpha}\right)
$$

The amount of water in the capillary pores $C_{w \text {-free }}$ is determined as a function of hydration degree as shown in

$$
C_{w \text {-free }}=\frac{W_{0}-0.4 * \alpha * C_{0}}{W_{0}}
$$

where $C_{0}$ and $W_{0}$ are the mass of cement and water in the mix proportion, respectively. The term $W_{0}-0.4 * \alpha * C_{0}$ in numerator considers the consumption of capillary water from cement hydration. 
TABLE 1: Coefficients of cement hydration model.

\begin{tabular}{lcccccccccc}
\hline $\begin{array}{l}B_{20} \\
(\mathrm{~cm} / \mathrm{h})\end{array}$ & $\begin{array}{c}C_{20} \\
(\mathrm{~cm} / \mathrm{h})\end{array}$ & $\begin{array}{c}k_{r C_{3} S 20} \\
(\mathrm{~cm} / \mathrm{h})\end{array}$ & $\begin{array}{c}k_{r C_{2} S 20} \\
(\mathrm{~cm} / \mathrm{h})\end{array}$ & $\begin{array}{c}k_{r C_{3} A 20} \\
(\mathrm{~cm} / \mathrm{h})\end{array}$ & $\begin{array}{c}k_{r C_{4} A F 20} \\
(\mathrm{~cm} / \mathrm{h})\end{array}$ & $\begin{array}{c}D_{e 20} \\
\left(\mathrm{~cm}^{2} / \mathrm{h}\right)\end{array}$ & $\begin{array}{c}\beta_{1} \\
(\mathrm{~K})\end{array}$ & $\begin{array}{c}\beta_{2} \\
(\mathrm{~K})\end{array}$ & $\begin{array}{c}\beta_{3} \\
(\mathrm{~K})\end{array}$ & $\begin{array}{c}E / R \\
(\mathrm{~K})\end{array}$ \\
\hline $8.1 \times 10^{-9}$ & 0.02 & $9.0 \times 10^{-6}$ & $2.7 \times 10^{-7}$ & $1.4 \times 10^{-6}$ & $6.8 \times 10^{-8}$ & $8.6 \times 10^{-10}$ & 1000 & 1000 & 7500 & 5400 \\
\hline
\end{tabular}

The influence of curing temperatures on reaction coefficients is described using Arrhenius's law as shown in

$$
\begin{aligned}
B & =B_{20} \exp \left(-\beta_{1}\left(\frac{1}{T}-\frac{1}{293}\right)\right), \\
C & =C_{20} \exp \left(-\beta_{2}\left(\frac{1}{T}-\frac{1}{293}\right)\right), \\
k_{r i} & =k_{r i 20} \exp \left(-\frac{E}{R}\left(\frac{1}{T}-\frac{1}{293}\right)\right), \\
D_{e} & =D_{e 20} \exp \left(-\beta_{3}\left(\frac{1}{T}-\frac{1}{293}\right)\right),
\end{aligned}
$$

where $\beta_{1}, \beta_{2}, E / R$, and $\beta_{3}$ represent temperature sensitivity coefficients and $B_{20}, C_{20}, k_{\text {rizo }}$, and $D_{e 20}$ denote the values of $B, C, k_{r i}$, and $D_{e}$ at $20^{\circ} \mathrm{C}$, respectively.
Using degree of reactions of mineral compounds of cement [13], the parameters of hydration model are calibrated and are shown in Table 1. Based on this Portland cement hydration model, Wang [12] evaluates chemically bound water, adiabatic temperature rising, and mechanical properties of high strength concrete incorporating Portland cement with different mineral compositions and different Blaine surfaces. The prediction results generally agree with experimental results.

2.2. Reaction Model of Slag. Maekawa et al. [14] measured the isothermal heat evolution rate of cement-slag paste. They found that the kinetic reaction process of slag is similar to that of cement. Slag reaction also consists of initial dormant period, boundary reaction process, and diffusion-controlled process. On the other hand, slag presents cementitious behavior (latent hydraulic activity) and pozzolanic behavior (reaction with lime). Slag reaction relates to capillary water contents and calcium hydroxide contents. Considering these points, we proposed that reaction of slag can be described as follows:

$$
\begin{aligned}
\frac{d \alpha_{\mathrm{SG}}}{d t} & =\frac{m_{\mathrm{CH}}(t)}{P} \frac{W_{\mathrm{cap}}}{W_{0}} \frac{3 \rho_{w}}{v_{\mathrm{SG}} r_{\mathrm{SG} 0} \rho_{\mathrm{SG}}} \frac{1}{\left(1 / k_{d \mathrm{SG}}-r_{\mathrm{SG} 0} / D_{e \mathrm{SG}}\right)+\left(r_{\mathrm{SG} 0} / D_{e S \mathrm{~S}}\right)\left(1-\alpha_{\mathrm{SG}}\right)^{-1 / 3}+\left(1 / k_{r \mathrm{SG}}\right)\left(1-\alpha_{\mathrm{SG}}\right)^{-2 / 3}}, \\
k_{d \mathrm{SG}} & =\frac{B_{\mathrm{SG}}}{\left(\alpha_{\mathrm{SG}}\right)^{1.5}}+C_{\mathrm{SG}} *\left(\alpha_{\mathrm{SG}}\right)^{3}, \\
D_{e \mathrm{SG}} & =D_{e \mathrm{SG} 0} * \ln \left(\frac{1}{\alpha_{\mathrm{SG}}}\right),
\end{aligned}
$$

where $\alpha_{\mathrm{SG}}$ denotes the degree of reaction of slag; $m_{\mathrm{CH}}(t)$ denotes the calcium hydroxide mass; $P$ denotes the mass of slag in the mixture proportion; $W_{\text {cap }}$ denotes the mass of capillary water; $v_{\mathrm{SG}}$ denotes the stoichiometric ratio of mass of $\mathrm{CH}$ to slag; $r_{\mathrm{SG} 0}$ denotes the radius of the slag particle; $\rho_{\mathrm{SG}}$ denotes the density of the slag; $k_{d \mathrm{SG}}$ denotes the reaction rate coefficient in the dormant period $\left(B_{\mathrm{SG}}\right.$ and $C_{\mathrm{SG}}$ are coefficients); $D_{e S G 0}$ denotes the initial diffusion coefficient; and $k_{r S G}$ denotes the reaction rate coefficient. In (6a), the term $m_{\mathrm{CH}}(t) / P$ considers the pozzolanic behavior of slag, and the term $W_{\text {cap }} / W_{0}$ considers the latent hydraulic activity of slag.

The influence of temperature on slag reaction is described by the Arrhenius law as follows:

$$
\begin{aligned}
& B_{\mathrm{SG}}=B_{\mathrm{SG} 20} \exp \left(-\beta_{1 \mathrm{SG}}\left(\frac{1}{T}-\frac{1}{293}\right)\right), \\
& C_{\mathrm{SG}}=C_{\mathrm{SG} 20} \exp \left(-\beta_{2 \mathrm{SG}}\left(\frac{1}{T}-\frac{1}{293}\right)\right),
\end{aligned}
$$

$$
\begin{aligned}
D_{e \mathrm{SG} 0} & =D_{e \mathrm{SG} 20} \exp \left(-\beta_{3 \mathrm{SG}}\left(\frac{1}{T}-\frac{1}{293}\right)\right), \\
k_{r \mathrm{SG}} & =k_{r \mathrm{SG} 20} \exp \left(-\frac{E_{\mathrm{SG}}}{R}\left(\frac{1}{T}-\frac{1}{293}\right)\right),
\end{aligned}
$$

where $B_{\mathrm{SG} 20}, C_{\mathrm{SG} 20}, D_{e \mathrm{SG} 20}$, and $k_{r \mathrm{SG} 20}$ denote the values of $B_{\mathrm{SG}}, C_{\mathrm{SG}}, D_{e S G}$, and $k_{r S \mathrm{SG}}$ at $20^{\circ} \mathrm{C}$, respectively and $\beta_{1 \mathrm{SG}}$, $\beta_{2 S G}, \beta_{3 S G}$, and $E_{\mathrm{SG}} / R$ denote the temperature sensitivity coefficients of $B_{\mathrm{SG}}, C_{\mathrm{SG}}, D_{e S G 0}$, and $k_{r \mathrm{SG}}$, respectively. The temperature sensitivity coefficients of slag can be regressed by using reaction degree of slag at different curing temperatures $[11,14]$.

In addition, besides chemical reaction, the addition of slag also presents dilution effect [12]. When slag is used as a mineral admixture, water to cement ratio will increase. For high strength concrete with a lower water to binder ratio, this dilution effect will be significant. In this paper, this dilution effect is considered through $C_{0} / W_{0}$ term in (4). 


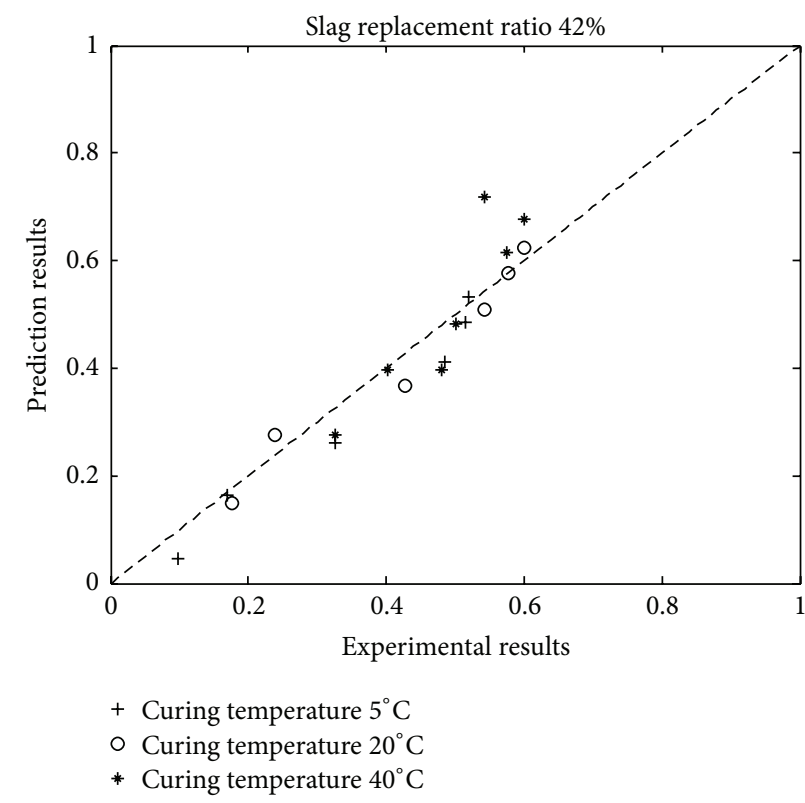

(a)

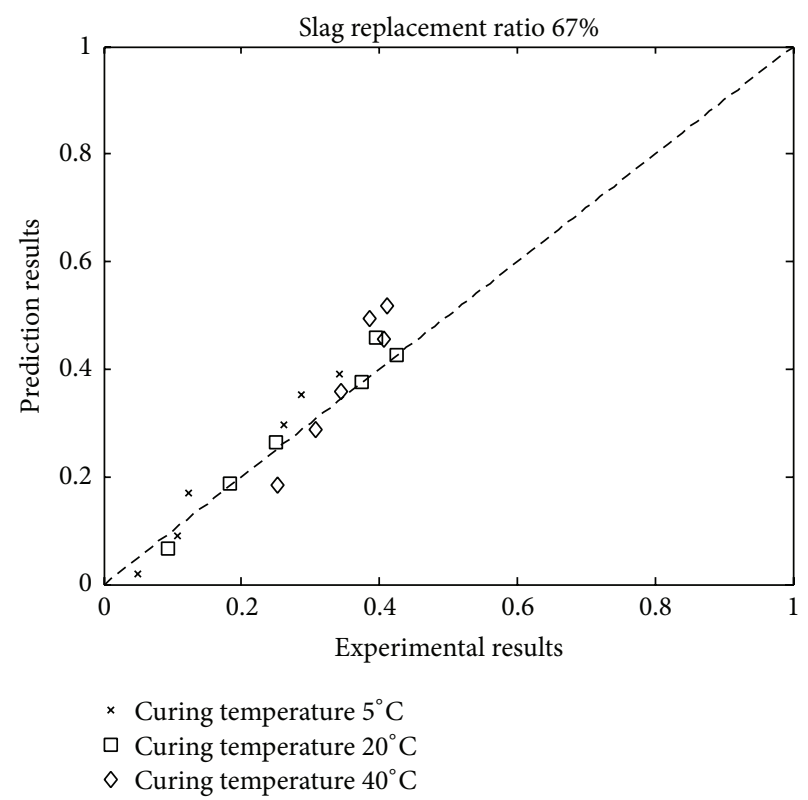

(b)

Figure 1: Reaction degree of slag with different slag replacement ratios and curing temperatures: (a) cement-slag paste with $42 \%$ slag; (b) cement-slag paste with $67 \%$ slag.

\subsection{Interaction Model between Cement Hydration and Slag} Reaction. Maekawa et al. [14] systematically analyzed the chemical, thermal, and mechanical properties of slag blended concrete. For the stoichiometry of slag reaction, Maekawa et al. summarized that when $1 \mathrm{~g}$ slag reacts, $0.22 \mathrm{~g}$ calcium hydroxide will be consumed; $0.30 \mathrm{~g}$ chemically bound water and $0.15 \mathrm{~g}$ physically bound water will be produced.

Considering the production of calcium hydroxide from cement hydration and the consumption of calcium hydroxide from slag reaction, the amounts of calcium hydroxide in cement-slag can be determined as follows:

$$
\mathrm{CH}=\mathrm{RCH}_{\mathrm{CE}} * C_{0} * \alpha-\mathrm{RCH}_{\mathrm{SG}} * \alpha_{\mathrm{SG}} * P,
$$

where $\mathrm{RCH}_{\mathrm{CE}}$ is the mass of produced calcium hydroxide from cement hydration and $\mathrm{RCH}_{\mathrm{SG}}$ is the mass of reacted calcium hydroxide in slag reaction.

Chemically bound water relates to both cement hydration and slag reaction. The chemically bound water contents can be determined as follows:

$$
W_{\mathrm{cbm}}=v * C_{0} * \alpha+\mathrm{RCW}_{\mathrm{SG}} * \alpha_{\mathrm{SG}} * P,
$$

where $\mathrm{RCW}_{\mathrm{SG}}$ is the mass of chemically bound water in slag reaction.

In cement-slag blends, capillary water will be consumed from cement hydration and slag reaction. The capillary water contents can be calculated as follows:

$$
\begin{aligned}
W_{\text {cap }}= & W_{0}-0.4 * C_{0} * \alpha-\mathrm{RCW}_{\mathrm{SG}} * \alpha_{\mathrm{SG}} * P \\
& -\mathrm{RPW}_{\mathrm{SG}} * \alpha_{\mathrm{SG}} * P,
\end{aligned}
$$

where $\mathrm{RPW}_{\mathrm{SG}}$ is the mass of gel water in the slag reaction.
Summarily, the proposed blended cement hydration model considers both cement hydration and slag reaction. The influences of water to binder ratios, slag replacement ratios, and curing temperatures on hydration are taken into account. The interactions between cement hydration and slag reaction are considered through calcium hydroxide content and capillary water contents. The reaction coefficients in hydration model are not changed with concrete mixing proportions. When water to binder ratio or slag replacement alters, these parameters of slag do not change.

2.4. Calibration and Parameter Study of Hydration Model. Iyoda et al. [15] measured slag reaction degrees in cementslag paste at different curing temperatures $\left(5^{\circ} \mathrm{C}, 20^{\circ} \mathrm{C}\right.$, and $40^{\circ} \mathrm{C}$ ) and slag substitution ratios $(42 \%$ and $67 \%$ mass percent). The water to binder ratio of paste is 0.5 . By using a selective dissolution method, the reaction degree of slag was measured at different curing ages. Using experimental results of reaction degree of slag [15], the reaction coefficients of slag are calibrated and shown in Table 2.

As shown in Figure 1, the prediction results generally agree with experimental results. Figure 2 shows parameter study about reaction degree of slag. The influences of slag replacement ratios, water to binder ratios, curing temperatures, and Blaine surface (fineness of slag) on reaction degree of slag are presented. As shown in Figure 2(a), with a reduction of the replacement level of slag, the alkaline activating effect of the cement would be greater, so that the reactivity of slag will increase. As shown in Figure 2(b), with an increase of water to binder ratio, there is more space available for hydration products to form; hence the reactivity of slag increases correspondingly. As shown in Figure 2(c), 
TABLE 2: Coefficients of slag reaction model.

\begin{tabular}{lccccccc}
\hline $\begin{array}{l}B_{20 S G} \\
(\mathrm{~cm} / \mathrm{h})\end{array}$ & $\begin{array}{c}C_{\mathrm{SG} 20} \\
(\mathrm{~cm} / \mathrm{h})\end{array}$ & $\begin{array}{c}k_{r \mathrm{SG} 20} \\
(\mathrm{~cm} / \mathrm{h})\end{array}$ & $\begin{array}{c}D_{e S G 20} \\
\left(\mathrm{~cm}^{2} / \mathrm{h}\right)\end{array}$ & $\begin{array}{c}\beta_{1 \mathrm{SG}} \\
(\mathrm{K})\end{array}$ & $\begin{array}{c}\beta_{2 S G} \\
(\mathrm{~K})\end{array}$ & $\begin{array}{c}\beta_{3 \mathrm{SG}} \\
(\mathrm{K})\end{array}$ & $\begin{array}{c}E_{\mathrm{SG}} / R \\
(\mathrm{~K})\end{array}$ \\
\hline $8.9 \times 10^{-9}$ & 0.1 & $1.0 \times 10^{-5}$ & $1.9 \times 10^{-9}$ & 1000 & 1000 & 5000 & 7000 \\
\hline
\end{tabular}

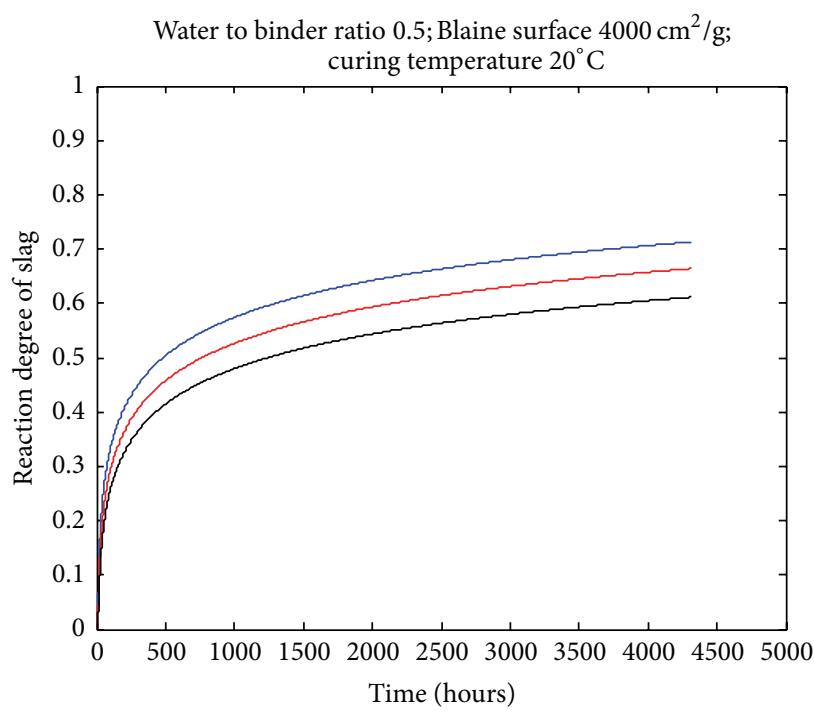

— Slag replacement ratio: 0.3

— Slag replacement ratio: 0.4

_ Slag replacement ratio: 0.5

(a) Slag replacement ratios

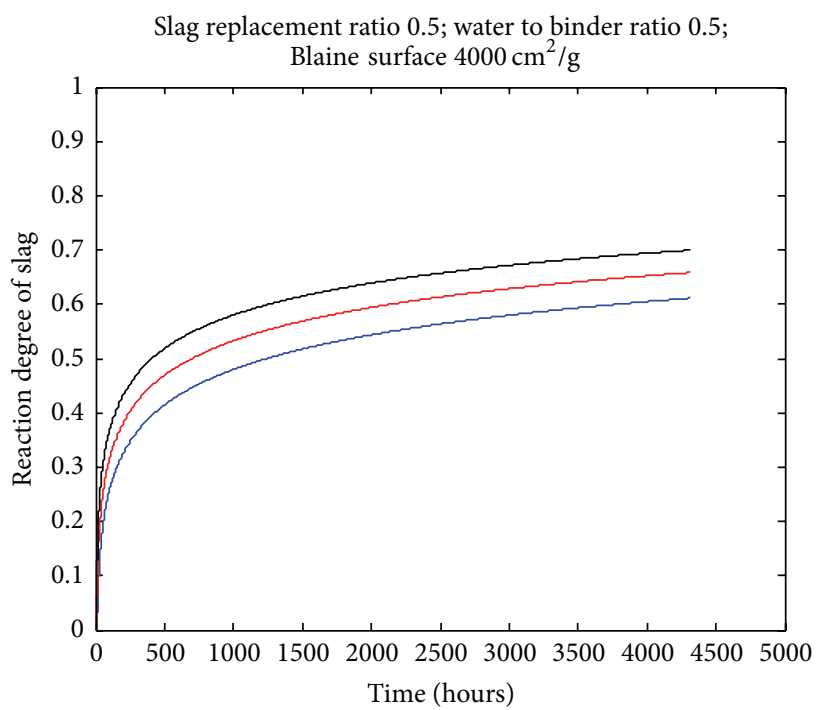

Curing temperature $20^{\circ} \mathrm{C}$
Curing temperature $30^{\circ} \mathrm{C}$
Curing temperature $40^{\circ} \mathrm{C}$

(c) Curing temperatures

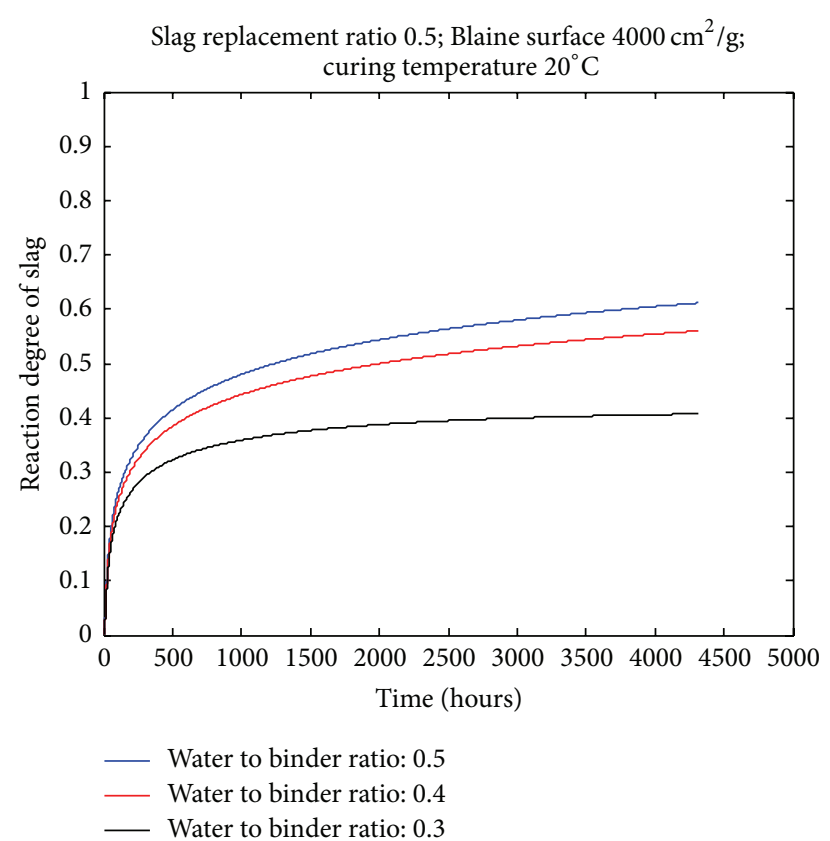

(b) Water to binder ratios

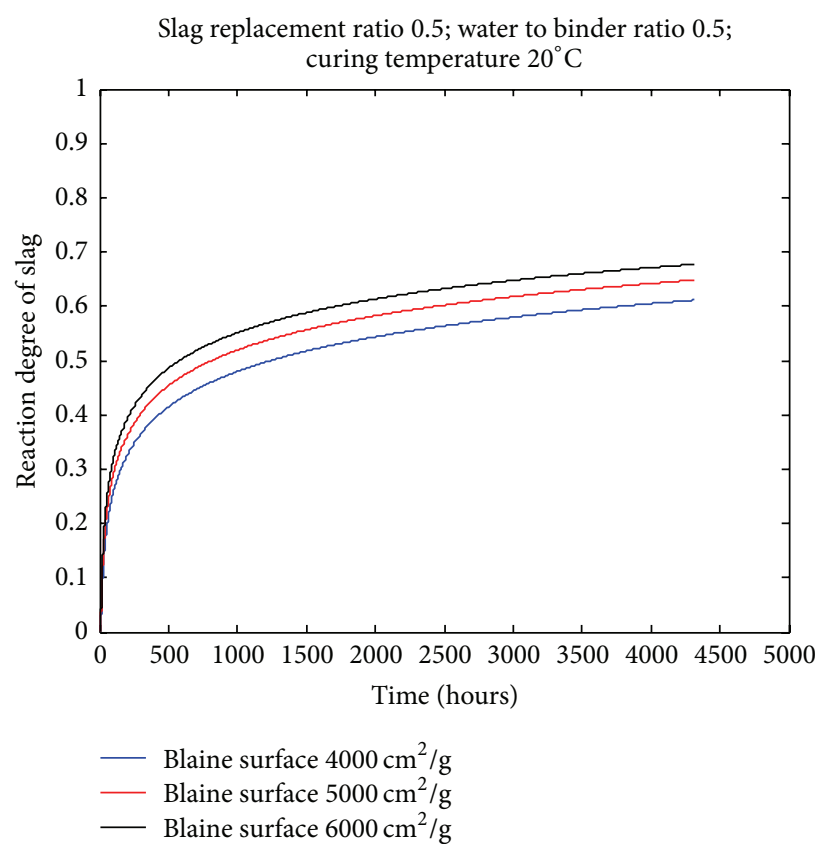

(d) Fineness of slag

Figure 2: Parameter study of reaction degree of slag: (a) slag replacement ratios; (b) water to binder ratios; (c) curing temperatures; and (d) fineness of slag (Blaine surface). 


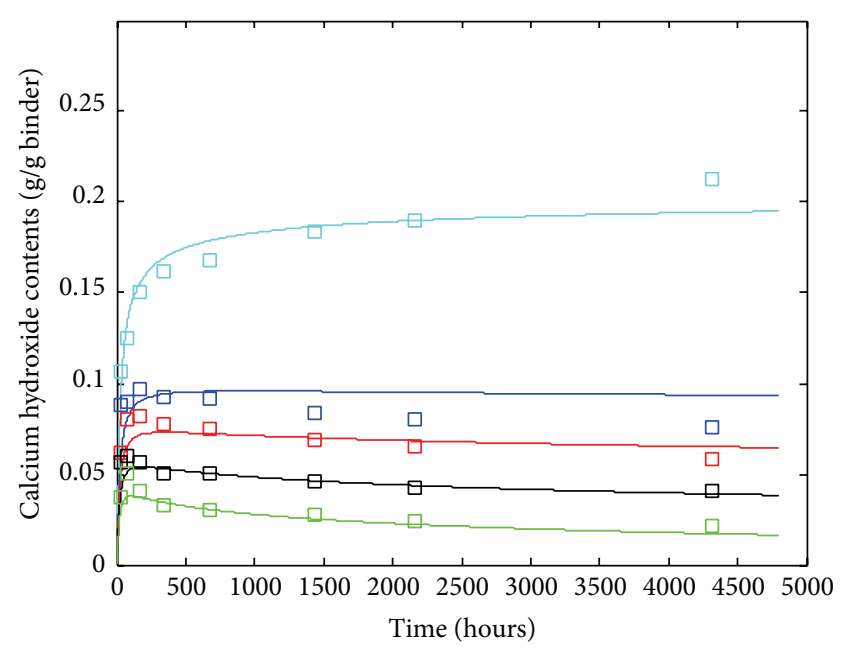

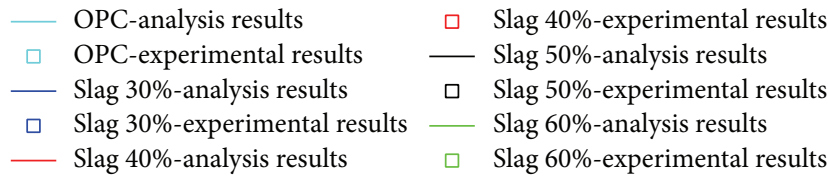

Figure 3: Evaluation of calcium hydroxide contents in cement-slag blends (water to binder ratio 0.5 ).

due to the increasing of curing temperatures, slag reaction will accelerate. As shown in Figure 2(d), with an increase of Blaine surface, slag particle will be much finer and the reactivity will be enhanced.

Zheng et al. [16] studied the evolution of calcium hydroxide contents in cement-slag blends. The water to binder ratio is 0.5 , slag replacement ratios vary between 0.3 and 0.6 , and the cement-slag paste specimens were cured at $20^{\circ} \mathrm{C}$. The amount of calcium hydroxide was estimated from the weight loss at $450-550^{\circ} \mathrm{C}$ using TG-DTA method at different curing ages. Using the proposed slag blended cement hydration model and reaction coefficients of cement and slag, the evolution of calcium hydroxide is calculated and shown in Figure 3. In the hydration of ordinary Portland cement, the mass of calcium hydroxide will increase before reaching a steady state. In the hydration of cement-slag blends, the evolution of the $\mathrm{CH}$ mass depends on two factors: the cement hydration which produces $\mathrm{CH}$ and the reaction of slag that consumes $\mathrm{CH}$. When slag replaces cement to a high percentage, the $\mathrm{CH}$ content may pass through a maximum level and then decrease.

The flowchart of modeling is summarized in Figure 4. At each time step, cement hydration degree and slag reaction degree are calculated. The capillary water contents, calcium hydroxide contents, and chemically bound water contents are calculated considering contributions from both cement hydration and slag reaction. Furthermore, using reaction degrees of cement and slag, volumetric stoichiometries of cement hydration and slag reaction, and mixing proportions of slag blended concrete, the gel-space ratio [17-20] and compressive strength development of hardening concrete can be calculated [17-20].

\section{Evaluation of Compressive Strength Development of Hardening Slag Blended Concrete}

3.1. Strength Development Model of Hardening Concrete. Wang [17, 18], Lam et al. [19], and Oh and Cha [20] proposed that the compressive strength of concrete depends on the gel/space ratio determined from degree of cement hydration and water to cement ratio. A gel/space ratio is defined as the ratio of the volumes of cement reaction products to the sum of the volumes of the hydrated cement and of the capillary pores. For cement-slag blends, the reaction products of binders consist of cement hydration products and slag reaction products. The gel/space ratio of cement-slag blends is given by

$$
x_{f c}=\frac{v(T)(1 / \rho) \alpha C_{0}+v_{\mathrm{SG}}(T)\left(1 / \rho_{\mathrm{SG}}\right) \alpha_{\mathrm{SG}} P}{(1 / \rho) \alpha C_{0}+\left(1 / \rho_{\mathrm{SG}}\right) \alpha_{\mathrm{SG}} P+W_{0}},
$$

where $x_{f c}$ is the gel/space ratio of blended cement pastes, $v(T)$ is the volume of hydration products of 1 unit volume cement, and $v_{\mathrm{SG}}(T)$ is the volume of reaction products of 1unit volume slag.

Wang [18] and van Breugel [21] proposed that, with the increasing of curing temperature, the thickness of reaction products layer decreases. Hence the values of $v(T)$ and $v_{\mathrm{SG}}(T)$ are not constant, but the decreasing functions of curing temperature are as follows $[18,21]$ :

$$
\begin{gathered}
v(T)=2.22 e^{-28 * 10^{-6} * T^{2}}, \\
v_{\mathrm{SG}}(T)=2.52 e^{-28 * 10^{-6} * T^{2}} .
\end{gathered}
$$

As shown in (10b) and (10c), the volume change of slag is larger than the anhydrous cement. This may be partially due to the lower density of slag hydration products and may indicate that slag reaction products are more effective in filling pores.

The development of compressive strength of Portland cement concrete can be calculated using Powers' strength theory as follows [18-21]:

$$
f_{c}(t)=A x_{f_{c}}^{n}
$$

where $f_{c}(t)$ is the compressive strength of concrete, $A$ is the intrinsic strength of the material, and $n$ is the strength exponent.

Powers' strength theory (see (10d)) is generally valid for Portland cement concrete. For slag blended concrete, due to the coexistence of cement hydration and slag reaction, the intrinsic strength of the material $A$ and strength exponent $n$ will relate to both cement hydration and slag reaction. For slag blended concrete with different slag contents, the intrinsic strength of the material $A$ and strength exponent $n$ will be different. Hence Powers' strength theory (see (10d)) cannot be used directly to evaluate strength development of slag blended concrete. 


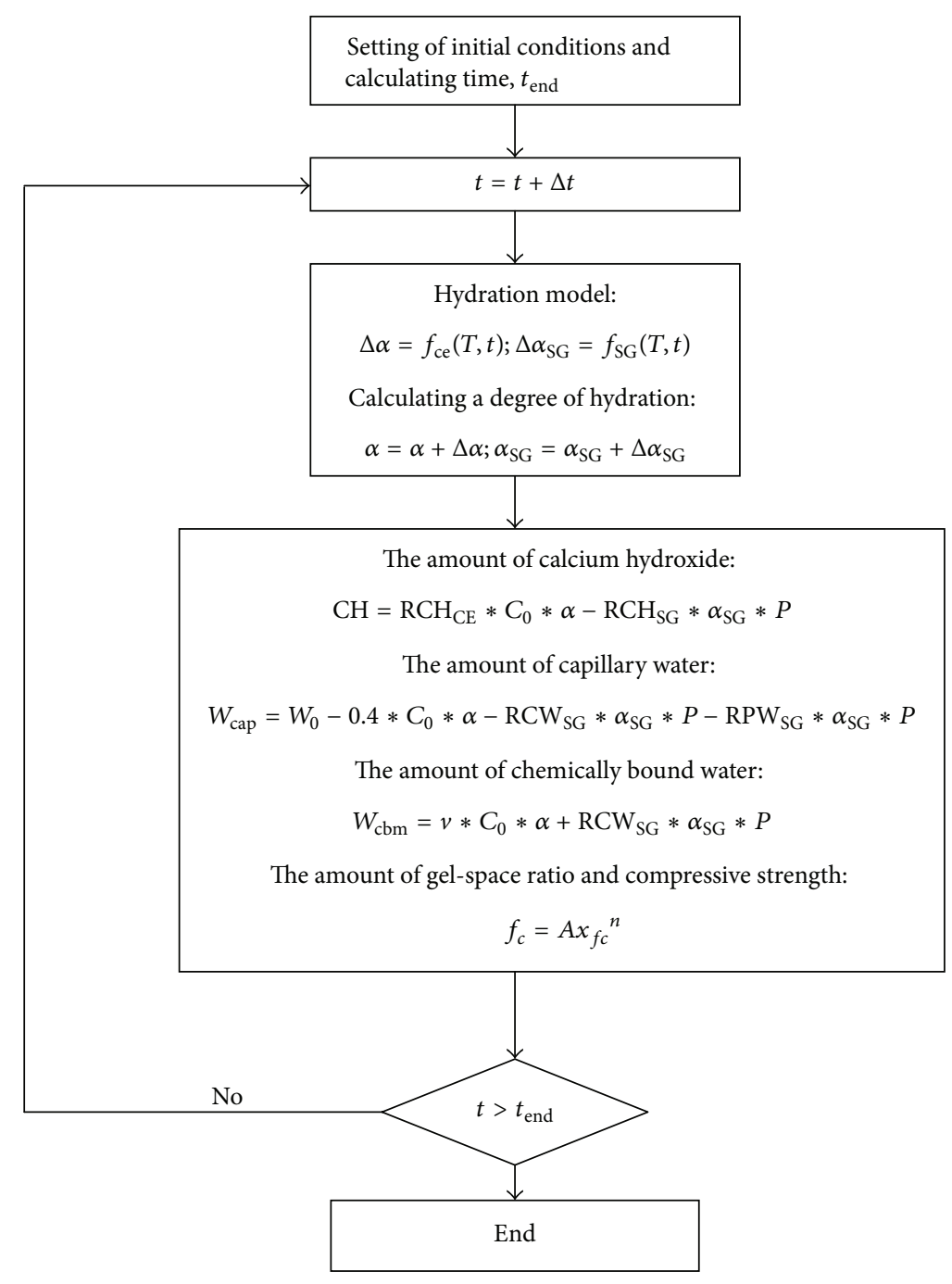

Figure 4: Flowchart of modeling.

To improve Powers' strength theory (see (10d)) for slag blended concrete, we simply assume that the intrinsic strength of the material $A$ and strength exponent $n$ can be expressed as a function of weight fractions of cement $\left(C_{0} /\right.$ $\left.\left(C_{0}+P\right)\right)$ and slag $\left(P /\left(C_{0}+P\right)\right)$ in the mixing proportion as follows:

$$
\begin{aligned}
& A=a 1 * \frac{C_{0}}{C_{0}+P}+a 2 * \frac{P}{C_{0}+P}, \\
& n=b 1 * \frac{C_{0}}{C_{0}+P}+b 2 * \frac{P}{C_{0}+P},
\end{aligned}
$$

where coefficients $a 1$ and $a 2$ in (10e) represent the contributions of cement and slag to the intrinsic strength of materials, respectively, the units of $a 1$ and $a 2$ are $\mathrm{MPa}$, and the coefficients $b 1$ and $b 2$ in (10f) represent the contributions of cement and slag to strength exponent, respectively. For Portland cement concrete, the weight fractions of slag are zero, and (10e) and (10f) are the same as Powers' strength theory (see (10d)).
Wang $[17,18]$ and Eren [5] found that, for low temperature casting, microstructure of the hydrated cement paste will be uniform, and the strength will be higher. Hence it is assumed that the ultimate strength of concrete (similar to intrinsic strength of concrete) is a decreasing function of curing temperature as follows:

$$
A=A_{20} * e^{-c *(T-20)},
$$

where $A_{20}$ is the intrinsic strength of concrete cured at $20^{\circ} \mathrm{C}$ and and strength reduction coefficient $c$ in the exponential part means that, with an increase of the curing temperature, the intrinsic strength of concrete $A$ will decrease.

For hardening concrete, the development of compressive strength relates to some competing factors: with the increasing of curing temperature, the rate of cement hydration and slag reaction will increase (see (5) and (6d) to $(6 g)$ ). Consequently, with the increase of curing temperatures, at a certain age, compressive strength of concrete will increase. On the other hand, when curing temperature increases, 
TABLE 3: Properties of binders.

\begin{tabular}{lccccccccccc}
\hline \multirow{2}{*}{ Material } & \multicolumn{1}{c}{ Oxide, percent } & \multicolumn{4}{c}{ Specific surface area } \\
& $\mathrm{CaO}$ & $\mathrm{SiO}_{2}$ & $\mathrm{Al}_{2} \mathrm{O}_{3}$ & $\mathrm{Fe}_{2} \mathrm{O}_{3}$ & $\mathrm{MgO}$ & $\mathrm{SO}_{3}$ & $\mathrm{~K}_{2} \mathrm{O}$ & $\mathrm{Na}_{2} \mathrm{O}$ & $\mathrm{MnO}$ & $\mathrm{TiO}_{2}$ & $\left(\mathrm{~m}^{2} / \mathrm{kg}^{2}\right.$ \\
\hline OPC & 65.8 & 20.5 & 5.8 & 2.5 & 1.2 & 2.3 & 0.6 & 0.3 & 0.1 & 0.2 & 391 \\
\hline Slag & 40.4 & 36.1 & 10.8 & 0.4 & 9.5 & 0.3 & 0.5 & 0.3 & 0.6 & 0.7 & 412 \\
\hline
\end{tabular}

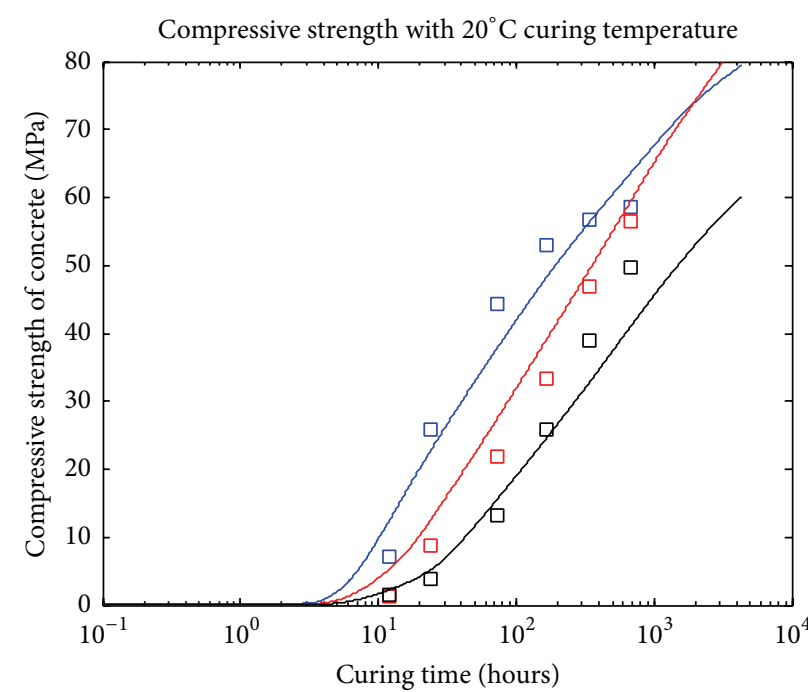

— OPC-prediction results

$\square \quad$ OPC-experimental results

— OPC 50\%-slag 50\%-prediction results

OPC 50\%-slag 50\%-experimental results

— OPC 30\%-slag 70\%-prediction results

口 OPC 30\%-slag 70\%-experimental results

FIGURE 5: Evaluation of compressive strength development of slag blended concrete at $20^{\circ} \mathrm{C}$ curing temperature.

the ratio between volume of reaction products and that of reacted binders will decrease (see (10b) to (10c)). In addition, when curing temperature increases, the ultimate strength of concrete will decrease (see $(10 \mathrm{~g})$ ). These factors will weaken the increasing trend of compressive strength. Summarily, based on the proposed blended cement hydration model and strength development model, we can model the strength crossover phenomenon for concrete with different curing temperatures.

3.2. Verifications of Proposed Model. Brooks and Al-Kaisi [9] studied the compressive strength development of slag blended concrete at elevated temperatures. The properties of binders are shown in Table 3. The first concrete was an OPC control mix having cement: fine aggregate: coarse aggregate mass proportions of $1: 1.62: 2.49$ with a water-cement ratio of 0.42 . The second and third concretes had 50 and 70 percent of the mass of OPC replaced by equal masses of slag, respectively, with the same aggregate proportions and watercementitious-materials ratio as the control concrete.

For each concrete, cubes were cast at $20^{\circ} \mathrm{C}$ cured in water tanks under two conditions: isothermal curing, where cubes were subjected to temperatures of 20,40 , and $47^{\circ} \mathrm{C}$; and heat-cycled curing, where the cubes were subjected to

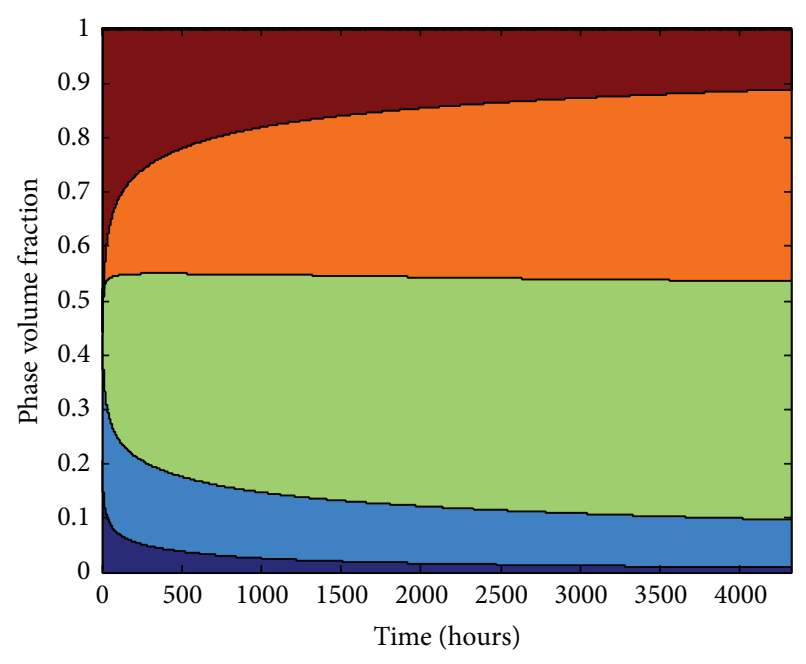

Volume of unhydrous cement $\square$ Slag reaction products Volume of unreacted slag Cement hydration products

Capillary porosity

Figure 6: Phase volume fractions of hardening slag-cement paste (water to binder ratio 0.5 , slag replacement ratio 0.5 ).

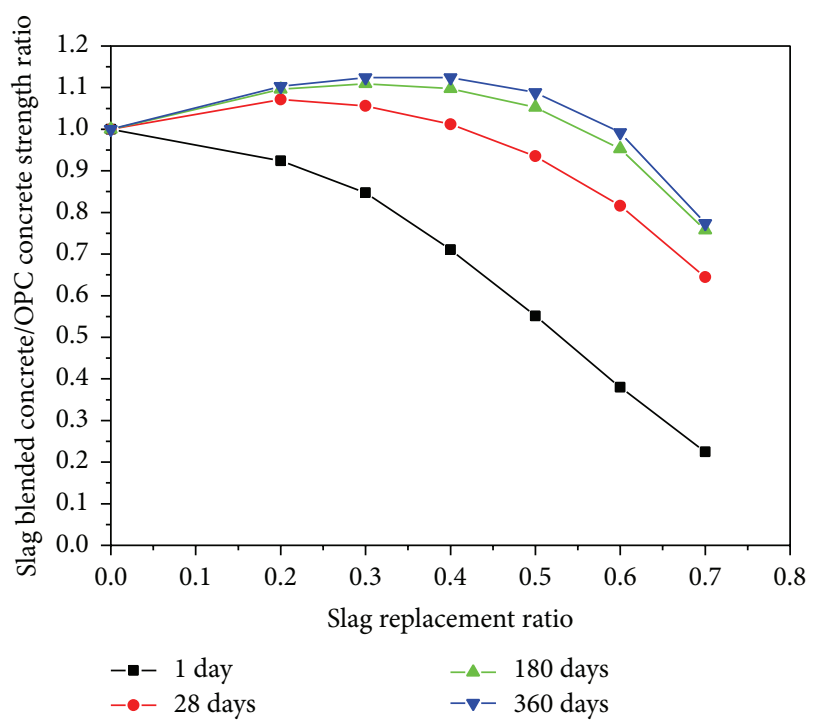

FIGURE 7: Effects of slag additions on strength development of concrete.

a controlled ascending temperature rise, and on reaching the peak temperature, the control system was switched off, and the cubes were allowed to cool to the ambient temperature. The amount of inhibitions of capillary water from surrounding moist curing related to the chemical shrinkage of hardening paste $[17,18]$. 


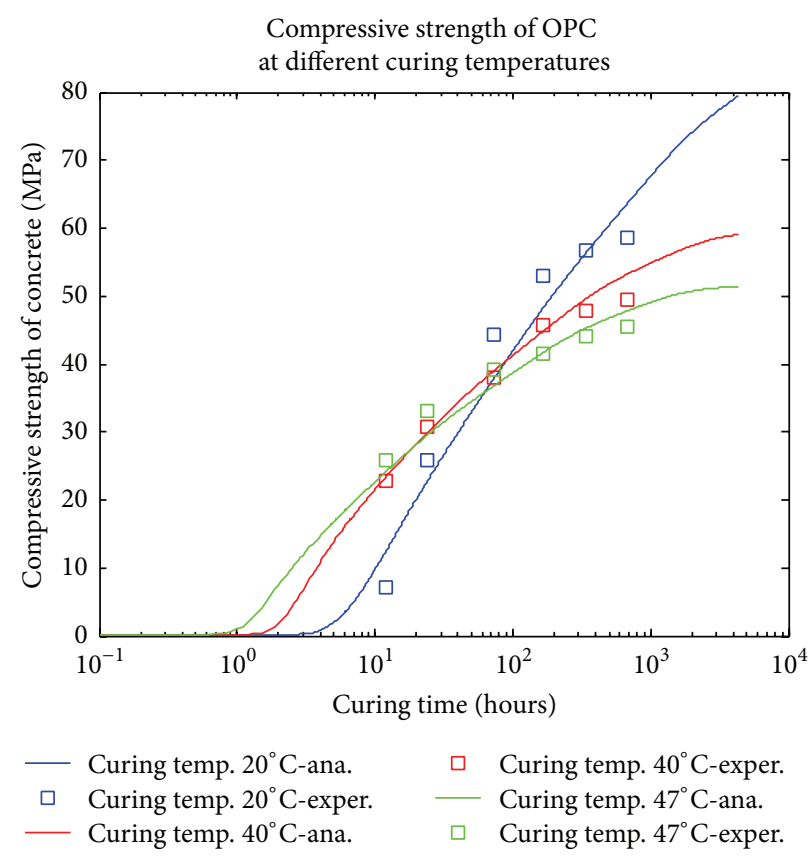

(a) OPC concrete at different curing temperatures

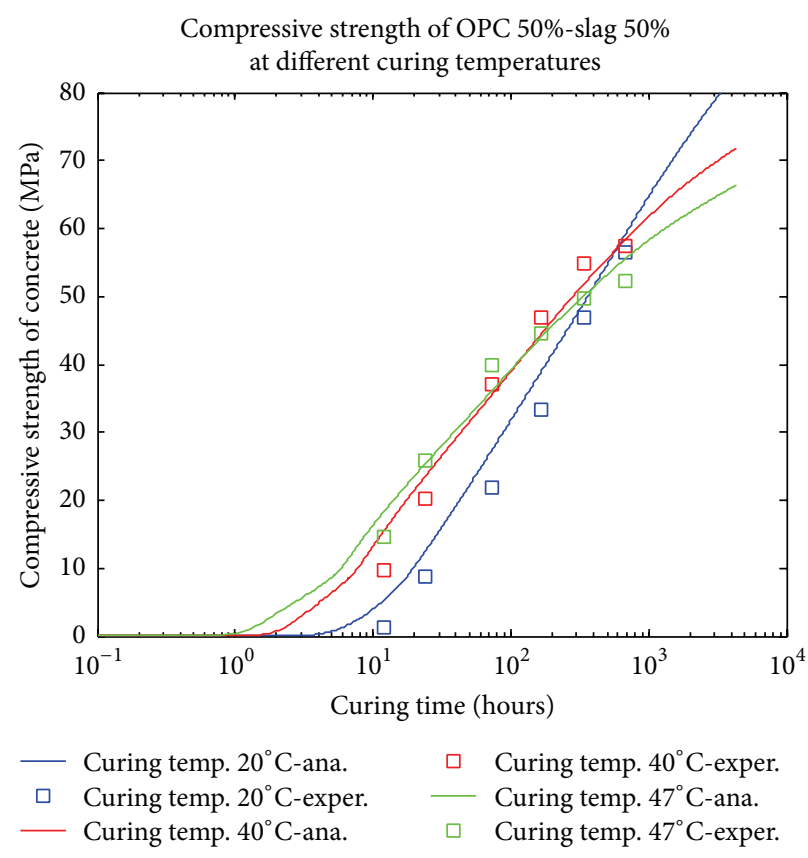

(b) Slag $50 \%$ concrete at different curing temperatures

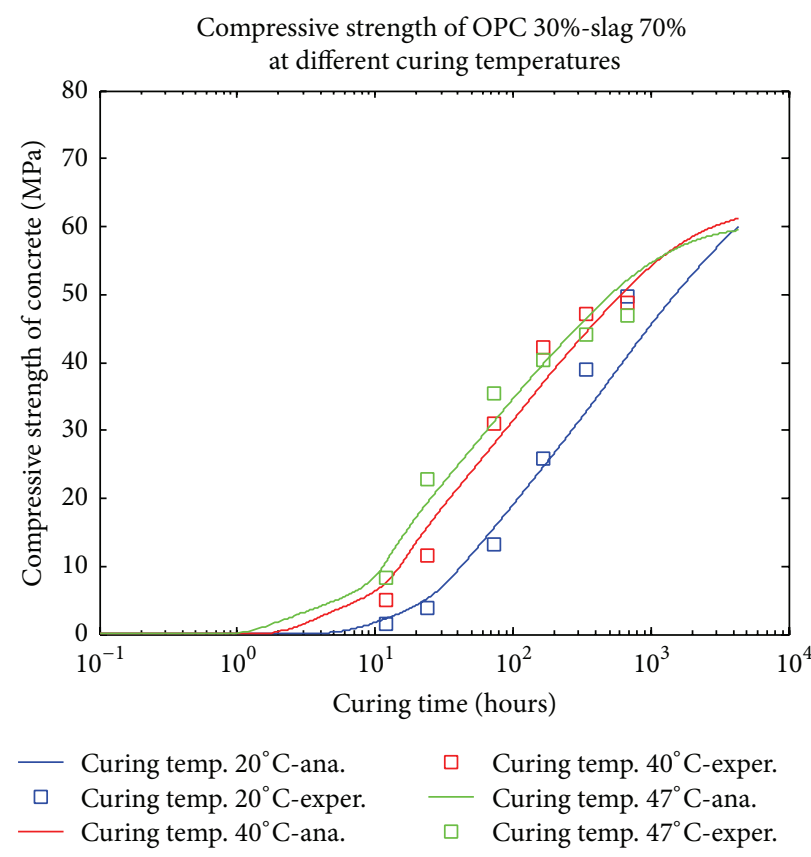

(c) Slag 70\% concrete at different curing temperatures

FIGURE 8: Strength development of concrete at different curing temperatures.

Using experimental results of compressive strength of concrete cured as $20^{\circ} \mathrm{C}$, the intrinsic strength coefficients in (10e) and strength exponent in (10f) can be calibrated as $a 1=103, a 2=123, b 1=2.11$, and $b 2=2.44$ (these coefficients do not vary with slag replacement ratio). As shown in Figure 5, for concrete incorporating 50\% slag, the early-age strength is lower than that of Portland cement concrete, and late age strength will surpass that of control concrete. Contrastively, for concrete incorporating 70\% slag, both early-age strength and late age strength are lower than those of control concrete. This is because the reactivity of slag decreases with the increasing of slag replacement ratio (shown in Figure 1).

The phase volume fractions of hardening slag-cement paste are shown in Figure 6 (water to binder ratio is 0.5, slag replacement ratio is 0.5 , and curing temperature is $20^{\circ} \mathrm{C}$ ). As shown in this figure, with the proceeding of hydration reactions, the volumes of unreacted cement and slag decrease, 
the volumes of reaction products increase, and the volume of capillary pore decrease. At early-age, hydration reactions proceed quickly, and at late age the reactions rate becomes slower.

Figure 7 presents parameter analysis about compressive strength development of concrete incorporating different slag contents. The water to binder is 0.42 and curing temperature is $20^{\circ} \mathrm{C}$, and the curing ages vary from 1 day to 360 days. The vertical axis represents the strength ratio of slag blended concrete to OPC at the same age. At an early age of 1 day, strength decreases as the slag ratio increases. This may be attributed to the lower reaction degree of slag. As the age increases, for concrete with higher slag ratios, the strength increases faster, and at a long-term age of 360 days, the maximum value of strength lies in the range of $30 \%-40 \%$ slag ratios. However, with regard to a slag ratio higher than $40 \%$, due to the lower reaction degree of slag, the ultimate strength ratio is less. Hence, for the binders used in this study, the optimum replacement ratio of slag is about $40 \%$. On the other hand, when the replacement ratio of slag is higher than $60 \%$, even at the late age of 360 days, the strength of slag concrete is yet lower than that of OPC due to the lower reaction degree of slag and lack of reaction products from slag reaction. So when the equivalent strength is necessary, the slag contents in binders should be less than $60 \%$.

Using experimental results of strength development of slag blended concrete at different isothermal curing temperatures, we can calibrate the strength reduction coefficient $c$ in $(10 \mathrm{~g})$. For OPC concrete, $50 \%$ slag blended concrete, and $70 \%$ slag blended concrete, the values of strength reduction coefficient $b$ are $0.014,0.009$, and 0.002 respectively. It is noticed that, with the increasing of curing temperature, the compressive strength of slag blended concrete decreases much slower than that of Portland cement concrete. This may be because of pore-size refinement and grain-size refinement effects from slag reactions [18]. The formation of slag reaction products can fill the large capillary voids and average pore size can be reduced. Also, due to the reaction between calcium hydroxide and slag, calcium hydroxide large grains can be decreased.

As shown in Figure 8, the proposed model can reproduce crossover phenomenon for compressive strength development of concrete at different curing temperatures. With the increasing of curing temperature, cement hydration and slag reaction will accelerate, and early-age strength of concrete will increase correspondingly. On the other hand, the increasing of curing temperature will make reaction products of cement and slag distribute inhomogeneously, larger capillary pores in concrete will increase, and the late age strength of concrete will reduce.

In addition, as shown in Figure 8(a) (OPC concrete) and Figure 8 (c) (70\% slag concrete), at late age, when the curing temperature is $20^{\circ} \mathrm{C}$, the compressive strength of OPC concrete is higher than that of $70 \%$ slag concrete; when the curing temperature is $40^{\circ} \mathrm{C}$, the compressive strength of $70 \%$ slag concrete is comparable with that of OPC concrete; and when the curing temperature is $47^{\circ} \mathrm{C}$, the compressive strength of $70 \%$ slag concrete is higher than that of OPC concrete. This is due to pore-size refinement and grain-size refinement

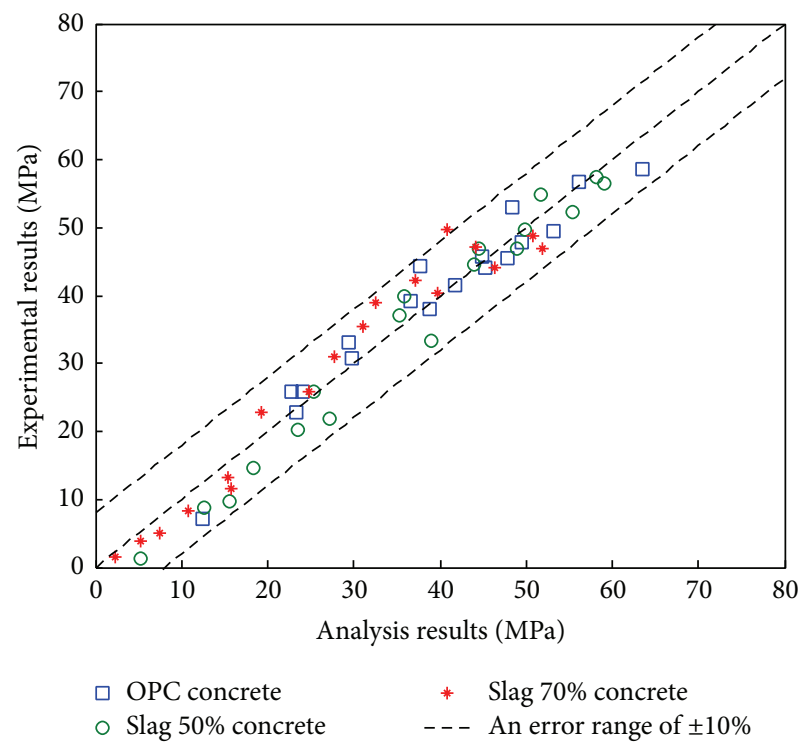

FIGURE 9: Comparsion between analysis results and experimental results.

effects from slag reactions. For concrete with elevated curing temperatures, strength of slag blended concrete decreases much slower than that of Portland cement concrete.

Figure 9 presents holistic comparison between evaluation results and experimental results. The evaluation results generally agree with experimental results. However, at very early age, the analysis results are slightly higher than that of experimental results. This is because of the ignorance of compressive strength threshold in the analysis process (when cement hydration degree is less than this threshold degree of hydration, compressive strength is zero).

For hardening concrete with time varying curing temperature, by using the differential expression of $(10 \mathrm{~d})$, the compressive strength development can be calculated. The curing temperature histories are shown in Figure 10. This curing temperature history is similar to actual temperature history of hardening mass concrete in construction site. The curing temperature of concrete first increases at a high rate; after reaching peak temperature, the temperature decreases slowly. As shown in Figure 11, the proposed model can reproduce the compressive strength development of control concrete and slag blended concrete with a time varying curing temperature. For the temperature history shown in Figure 11, the late strength of $70 \%$ slag blended concrete (Figure 11(b)) is slightly higher than that of control Portland cement concrete (Figure $11(\mathrm{a})$ ). While for $20^{\circ} \mathrm{C}$ curing temperature, as shown in Figures 5 and 7, the compressive strength of 70\% slag concrete is always lower than that of control concrete. This is because the strength reduction coefficient of OPC is much higher than that of slag blended concrete. Hence, with the increasing of curing temperature, OPC concrete shows more strength loss than that of slag blended concrete.

In addition, it should be noticed that the proposed model is generally valid for normal strength concrete. For ultrahigh strength concrete, aggregate will contribute to compressive 


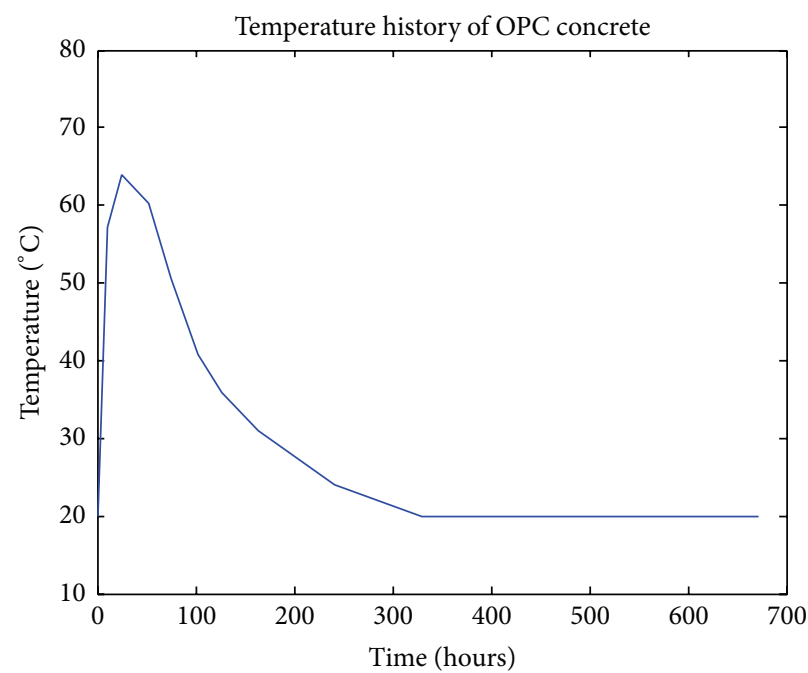

(a) Temperature histroy of OPC concrete

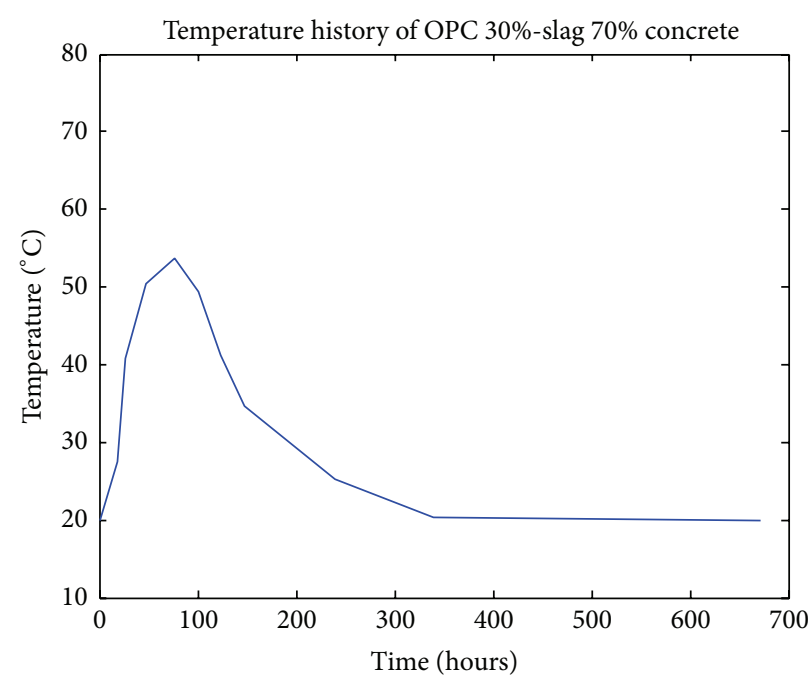

(b) Temperature histroy of slag $70 \%$ concrete

FIGURE 10: Temperature history of hardening concrete.

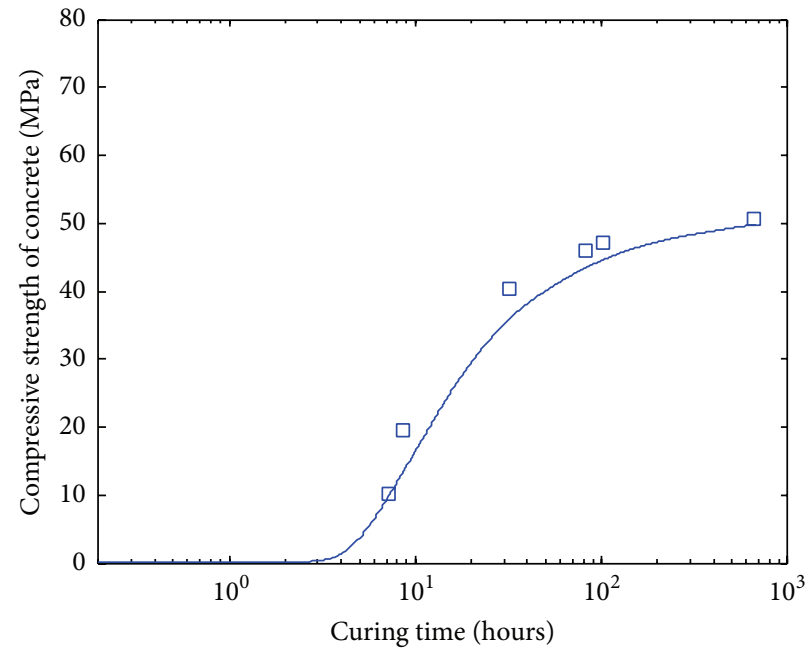

- OPC-analysis results

$\square \quad$ OPC-experimental results

(a) Strength development of OPC concrete at time varying curing temperature

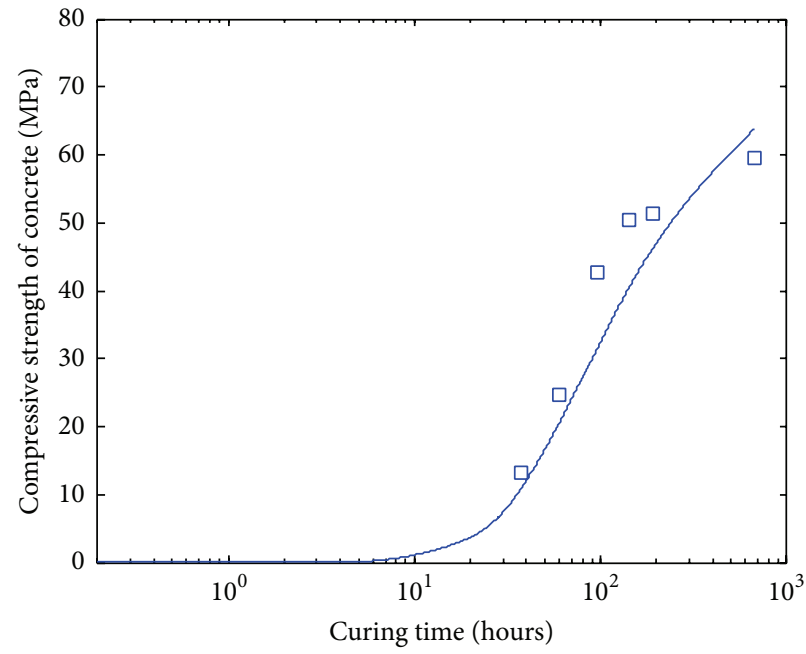

OPC 30\%-slag 70\%-analysis results

OPC 30\%-slag 70\%-experimental results

(b) Strength development of slag $70 \%$ concrete at time varying curing temperature

FIGURE 11: Strength development of concrete at time varying curing temperature.

strength. To accurately evaluate strength development of hardening concrete, composite model which simulates interactions between cement paste and aggregate is necessary [1921].

\section{Conclusions}

This paper presents a numerical procedure to simulate cement hydration, slag reaction, microstructure development, and strength development of slag blended concrete. Cement hydration model and slag reaction model are simulated separately. The interactions between cement hydration and slag reaction are considered through available capillary water contents and calcium hydroxide contents in cementslag blends system. Furthermore, using reaction degrees of cement and slag, volumetric stoichiometries of cement hydration and slag reaction and mixing proportions of slag blended concrete, the gel-space ratio and strength development of hardening concrete are determined.

The proposed model considers both strengthening factors and weakening factors involved in strength development process of slag blended concrete: due to the increase of curing temperature, cement hydration and slag reaction are accelerated, the ratios between the volume of reaction products and that of reacted binders decrease, and the ultimate strength of concrete is reduced. The proposed procedure can reproduce 
strength crossover phenomenon of hardening concrete with low curing temperatures and high curing temperatures. The proposed model is valid for concrete with different slag contents, different curing temperatures, and time varying temperature history.

\section{Competing Interests}

The authors declare that they have no competing interests.

\section{Acknowledgments}

This research was supported by a grant (13SCIPA02) from Smart Civil Infrastructure Research Program funded by Ministry of Land, Infrastructure and Transport (MOLIT) of Korea Government and Korea Agency for Infrastructure Technology Advancement (KAIA).

\section{References}

[1] Y.-Y. Kim, K.-M. Lee, J.-W. Bang, and S.-J. Kwon, "Effect of W/C ratio on durability and porosity in cement mortar with constant cement amount," Advances in Materials Science and Engineering, vol. 2014, Article ID 273460, 11 pages, 2014.

[2] X.-Y. Wang and H.-S. Lee, "Modeling the hydration of concrete incorporating fly ash or slag," Cement and Concrete Research, vol. 40, no. 7, pp. 984-996, 2010.

[3] A. A. Ramezanianpour and V. M. Malhotra, "Effect of curing on the compressive strength, resistance to chloride-ion penetration and porosity of concretes incorporating slag, fly ash or silica fume," Cement \& Concrete Composites, vol. 17, no. 2, pp. 125-133, 1995.

[4] Y. Luan, T. Ishida, T. Nawa, and T. Sagawa, "Enhanced hydration model and simulation of hydration process of blast furnace slag in blended cement," Proceedings of Japan Concrete Institute, vol. 33, pp. 71-76, 2011.

[5] Ö. Eren, "Strength development of concretes with ordinary Portland cement, slag or fly ash cured at different temperatures," Materials and Structures, vol. 35, no. 253, pp. 536-540, 2002.

[6] V. G. Papadakis and S. Tsimas, "Supplementary cementing materials in concrete: part I: efficiency and design," Cement and Concrete Research, vol. 32, no. 10, pp. 1525-1532, 2002.

[7] V. G. Papadakis, S. Antiohos, and S. Tsimas, "Supplementary cementing materials in concrete. Part II: a fundamental estimation of the efficiency factor," Cement and Concrete Research, vol. 32, no. 10, pp. 1533-1538, 2002.

[8] T. Ishida, Y. Luan, T. Sagawa, and T. Nawa, "Modeling of early age behavior of blast furnace slag concrete based on microphysical properties," Cement and Concrete Research, vol. 41, no. 12, pp. 1357-1367, 2011.

[9] J. J. Brooks and A. F. Al-Kaisi, "Early strength development of portland and slag cement concretes cured at elevated temperatures," ACI Materials Journal, vol. 87, no. 5, pp. 503-507, 1990.

[10] S. J. Barnett, M. N. Soutsos, J. H. Bungey, and S. G. Millard, "Fast-track construction with slag cement concrete: adiabatic strength development and strength prediction," ACI Materials Journal, vol. 104, pp. 388-396, 2007.

[11] F. Tomosawa, "Development of a kinetic model for hydration of cement," in Proceedings of the 10th International Congress Chemistry of Cement, S. Chandra, Ed., Gothenburg, Sweden, 1997.
[12] X. Y. Wang, "Properties prediction of fly ash blended concrete using hydration model," Science China Technological Sciences, vol. 56, no. 9, pp. 2317-2325, 2013.

[13] T. Matsushita, S. Hoshino, I. Maruyama, T. Noguchi, and K. Yamada, "Effect of curing temperature and water to cement ratio on hydration of cement compounds," in Proceedings of the 12th International Congress on the Chemistry of Cement, J. Beaudoin, Ed., Montreal, Canada, 2007.

[14] K. Maekawa, T. Ishida, and T. Kishi, Multi-Scale Modeling of Structural Concrete, Taylor \& Francis, London, UK, 2009.

[15] T. Iyoda, K. Inokuchi, and T. Uomoto, "Effect of slag hydration of blast furnace slag cement in different curing conditions," in Proceedings of 13th International Congress on the Chemistry of Cement, A. Palomo, A. Zaragoza, and J. C. L. Agui, Eds., Madrid, Spain, 2011.

[16] K. R. Zheng, W. Sun, Y. T. Jia, Y. S. Zhang, and Y. Zhang, "Approaches to the appropriate admixture of Slag based on hydration of slag cement system," Architecture Technology, vol. 36, pp. 39-40, 2005.

[17] X.-Y. Wang, "Evaluation of compressive strength of hardening silica fume blended concrete," Journal of Materials Science, vol. 48, no. 17, pp. 5953-5961, 2013.

[18] X.-Y. Wang, "Properties prediction of ultra high performance concrete using blended cement hydration model," Construction and Building Materials, vol. 64, pp. 1-10, 2014.

[19] L. Lam, Y. L. Wong, and C. S. Poon, "Degree of hydration and gel/space ratio of high-volume fly ash/cement systems," Cement and Concrete Research, vol. 30, no. 5, pp. 747-756, 2000.

[20] B. H. Oh and S. W. Cha, "Nonlinear analysis of temperature and moisture distributions in early-age concrete structures based on degree of hydration," ACI Materials Journal, vol. 100, no. 5, pp. 361-370, 2003.

[21] K. van Breugel, Simulation of Hydration and Formation of Structure in Hardening Cement-Based Materials, Delft University Press, 1997. 

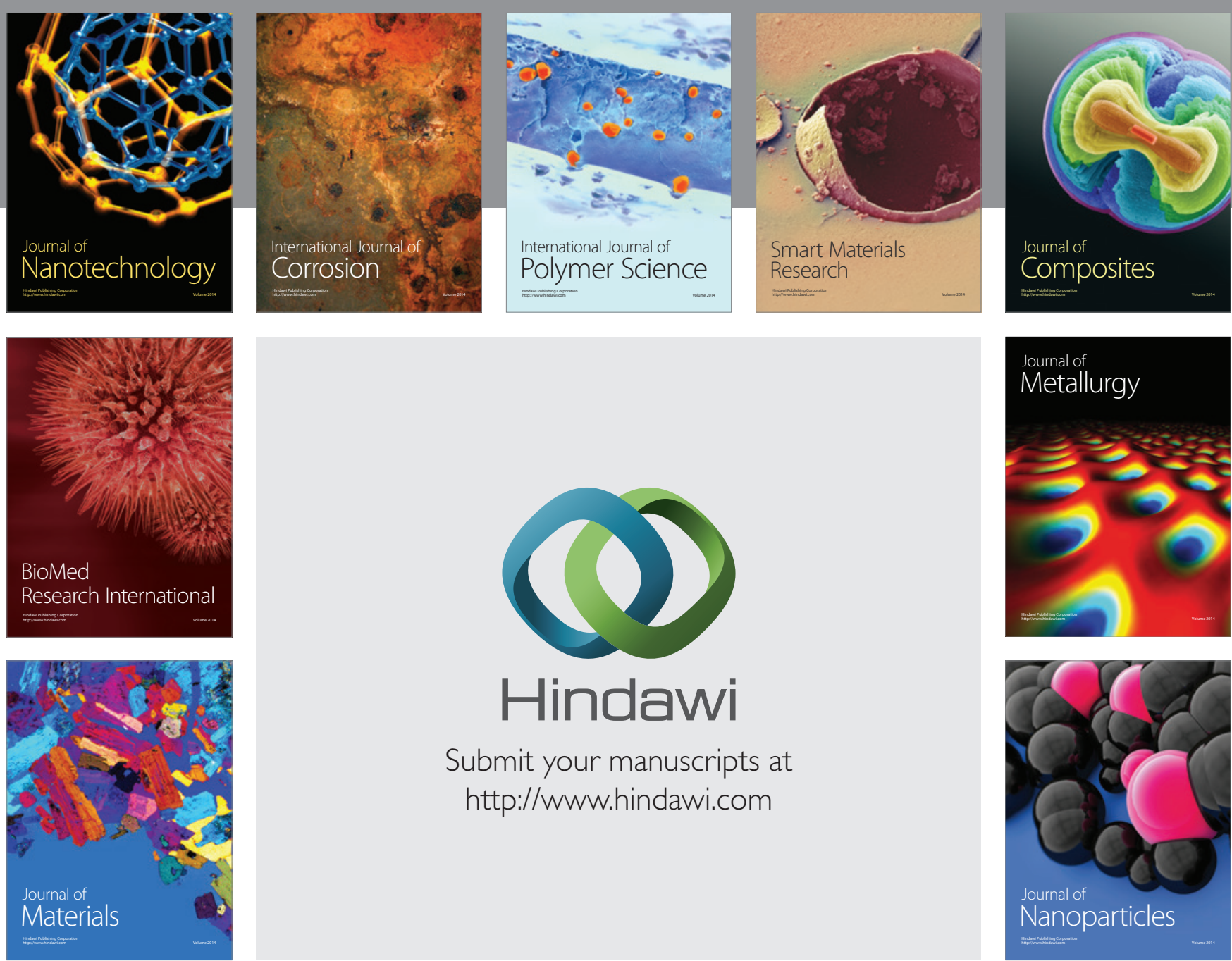

\section{Hindawi}

Submit your manuscripts at

http://www.hindawi.com

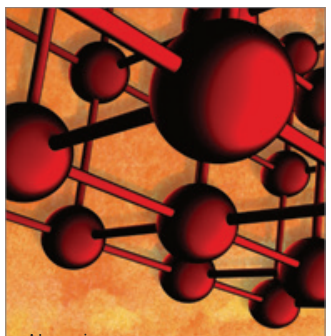

Materials Science and Engineering
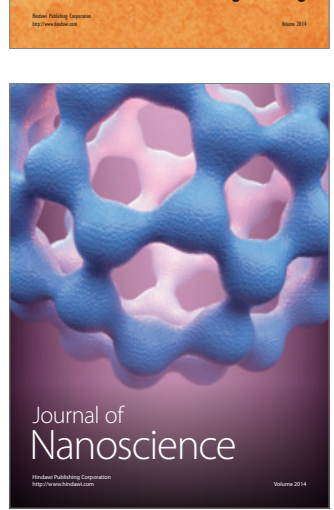
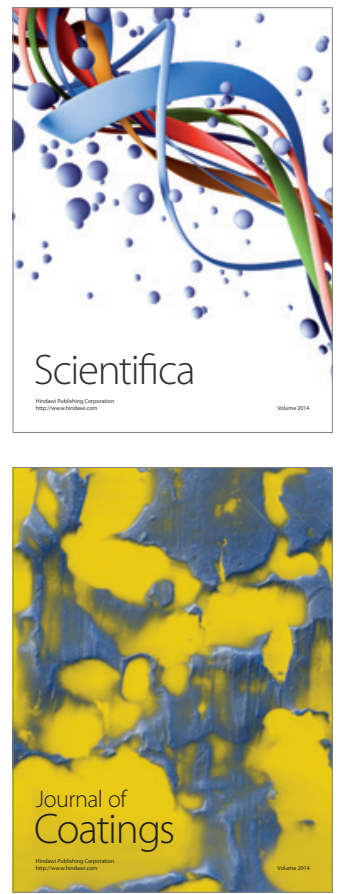
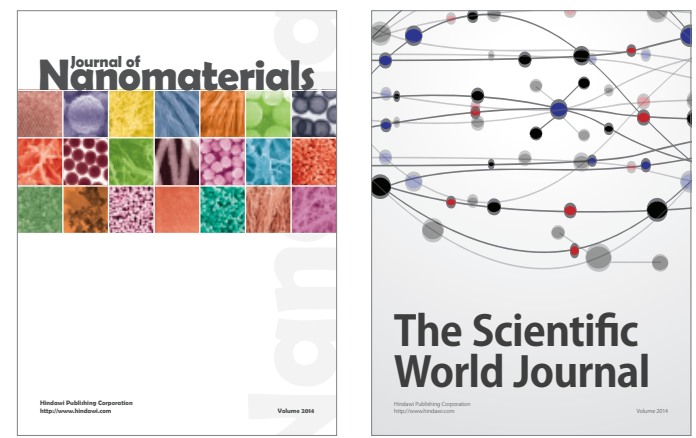

The Scientific World Journal
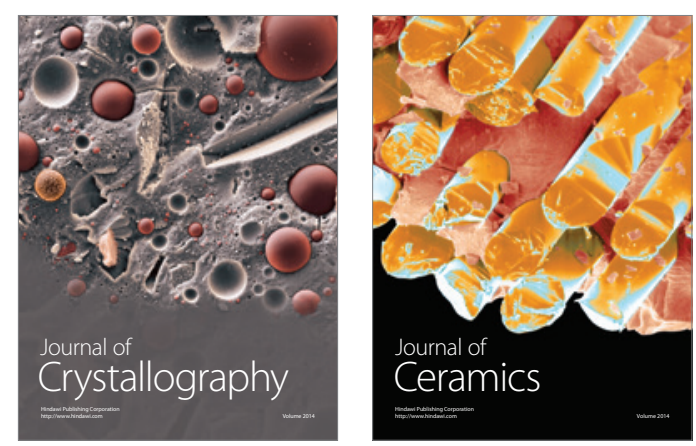
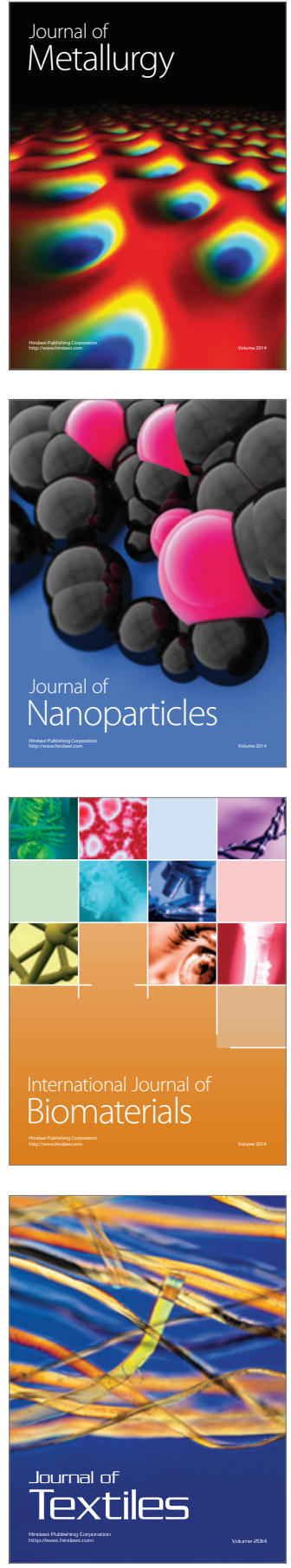